\section{Immune-mediated necrotizing myopathies and interstitial lung disease are predominant characteristics in anti-Ku positive patients with idiopathic inflammatory myopathies}

We read an interesting study by Spielmann et al conducted on a single-centre large French cohort, which identified that anti-Ku autoantibodies were effective biomarkers for two distinct connective tissue diseases (CTDs): anti-Ku-positive patients with elevated serum creatine kinase (CK) levels had a high risk for developing interstitial lung diseases (ILD), while anti-Ku-positive patients with anti-double-strand DNA were at high risk for developing glomerulonephritis. ${ }^{1}$ Anti-Ku autoantibodies are associated with various CTDs, such as systemic lupus erythematosus, systemic sclerosis, idiopathic inflammatory myopathies (IIM), mixed CTDs, Sjögren's syndrome, and rheumatoid arthritis. However, few studies have focused on the distinguishing features, especially the pathological features of IIM patients with isolated anti-Ku and anti-Ku coexistence with myositis-specific autoantibodies (MSA).

Here, we retrospectively investigated the characteristics of 1214 IIM patients with anti-Ku autoantibodies, all fulfilling the Bohan \& Peter criteria for IIM and admitted to the Department of Rheumatology at China-Japan Friendship Hospital from January 2008 to July 2019. Anti-Ku autoantibodies were detected by line immunoassay (EUROLINE, Germany) and ELISA assay (Enzyme-linked Biotechnology, China) in the sera of 156 patients with anti-nuclear antibodies of titres $\geq 1 / 160$ showing fine speckled patterns on immunofluorescence assay of HEp-2 cells. Finally, 21 patients were confirmed to be antiKu-positive by line immunoassay and ELISA assay. Meanwhile, MSA and anti-3-hydroxy-3-methylglutaryl-CoA reductase autoantibody levels in the sera of anti-Ku-positive patients were measured using line immunoassay (EUROLINE, Germany) and ELISA assay (Raybiotech, China). Muscle biopsy was performed in 13 of 21 anti-Ku-positive patients.

The incidence of anti-Ku autoantibodies was $1.73 \%$ in our IIM cohort. Twenty out of 21 patients were women. The average age of onset was $42.60 \pm 14.35$ years. Eight patients were diagnosed with dermatomyositis (DM), 11 with polymyositis (PM), and two overlapping with SSc. Eleven patients (52.4\%) showed isolated anti-Ku antibodies, the others $(47.6 \%)$ coexistence of anti-Ku with MSA. Skin involvement was less common among patients with isolated anti-Ku than that among patients showing coexistence of anti-Ku and MSA (18.2\% vs $70 \%, \mathrm{p}=0.03)$. ILD presented in $76.2 \%$ of anti-Ku-positive IIM patients, consistent with the high frequency of ILD reported in previous studies. ${ }^{12}$ Although there was no significant difference in the incidence of ILD between patients with isolated anti-Ku and anti-Ku coexistence with MSA, patients with isolated anti-Ku had a lower mean percentage of predicted value for FVC and DLco than those with coexistence of anti-Ku and MSA(74.05\% $\pm 12.84 \%$ vs $93.21 \pm 18.54 \%$ and $59.61 \pm 15.41 \%$ vs $76.03 \pm 14.15 \%$, $\mathrm{p}=0.035$ and 0.049 , respectively). Increased CK level was observed in $90.9 \%(10 / 11)$ of patients with isolated anti-Ku and $50 \%(5 / 10)$ of those with coexistence of anti-Ku and MSA (table 1).

In the previous studies on French and Japanese cohorts, the musculoskeletal histopathological performance of only 22 IIM patients with anti-Ku-positive was described. ${ }^{3-5}$ The main pathological features were muscle fibre necrosis $(18 / 22,81.8 \%)$ and major histocompatibility complex (MHC) class I expression
Table 1 Characteristics of anti-Ku-positive patients with IIM

\begin{tabular}{|c|c|c|}
\hline Features & $\begin{array}{l}\text { Isolated anti-Ku } \\
(\mathrm{n}=11)\end{array}$ & $\begin{array}{l}\text { Coexistence of anti-Ku and } \\
\text { MSA }(n=10)\end{array}$ \\
\hline Female & $10(90.9 \%)$ & $10(100 \%)$ \\
\hline Age of onset & $45.55 \pm 16.45$ & $39.00 \pm 11.47$ \\
\hline Duration(months) & $12(3,72)$ & $29(4,60)$ \\
\hline \multicolumn{3}{|l|}{ Diagnosis } \\
\hline DM & $2(18.2 \%)$ & $6(60 \%)$ \\
\hline PM & $8(72.7 \%)$ & $3(30 \%)$ \\
\hline $\mathrm{PM}+\mathrm{SSC}$ & $1(9.1 \%)$ & 0 \\
\hline $\mathrm{DM}+\mathrm{SSC}$ & 0 & $1(10 \%)$ \\
\hline \multicolumn{3}{|l|}{ MSA } \\
\hline MDA5 & - & $3(14.8 \%)$ \\
\hline NXP2 & - & $1(4.8 \%)$ \\
\hline TIF1 $\gamma$ & - & $2(9.5 \%)$ \\
\hline Jo-1 & - & $1(4.8 \%)$ \\
\hline PL-12 & - & $1(4.8 \%)$ \\
\hline PL-7 & - & $1(4.8 \%)$ \\
\hline SRP & - & $1(4.8 \%)$ \\
\hline \multicolumn{3}{|l|}{ MAA } \\
\hline Ro-52 & $1(9.1 \%)$ & $5(50 \%)$ \\
\hline PM-SCl 75/100 & 0 & $2(20 \%)$ \\
\hline Muscle Weakness & $8(72.7 \%)$ & $8(80 \%)$ \\
\hline Dysphagia & $2(18.2 \%)$ & $5(50 \%)$ \\
\hline Neck weakness & $1(8.3 \%)$ & $1(10 \%)$ \\
\hline Myalgia & $6(54.5 \%)$ & $4(40 \%)$ \\
\hline Skin involvement* & $2(18.2 \%)$ & $7(70 \%)$ \\
\hline Raynaud's phenomena & $3(27.3 \%)$ & $2(20 \%)$ \\
\hline ILD & $8(72.7 \%)$ & $8(80 \%)$ \\
\hline FVC\% of predicted valuet & $74.05 \pm 12.84$ & $93.21 \pm 18.54$ \\
\hline DLco $\%$ of predicted value & $59.61 \pm 15.41$ & $76.03 \pm 14.15$ \\
\hline Arthritis & $3(25 \%)$ & $2(20 \%)$ \\
\hline Cancer & 0 & 0 \\
\hline Increased CK & $10(90.9 \%)$ & $5(50 \%)$ \\
\hline Pathological pattern & $n=7$ & $\mathrm{n}=6$ \\
\hline IMNM & 6 & 1 (anti-PL-7 positive) \\
\hline pDM & 0 & $\begin{array}{l}2 \text { (anti-MDA5 and -TIF1 } \gamma \\
\text { positive) }\end{array}$ \\
\hline NSM & 1 & 1(anti-Jo-1 positive) \\
\hline Normal & 0 & $\begin{array}{l}2 \text { (anti-MDA5 and -TIF1 } \gamma \\
\text { positive) }\end{array}$ \\
\hline
\end{tabular}

FVC and DLco value were available for 8 patients with isolated anti-Ku and 7 patients with anti-Ku coexistence of MSA.

${ }^{*} \mathrm{P}=0.03$.

$+\mathrm{P}=0.035$

$\ddagger \mathrm{P}=0.049$.

CK, creatine kinase; DLco, carbon monoxide diffusion capacity; DM, dermatomyositis; FVC, forced vital capacity; ILD, interstitial lung disease; IMNM, immune-mediated necrotizing myopathie; MAA, myositis-associated autoantibodies; MSA, myositis-specific autoantibodies; NSM, non-specific myositis; pDM, pathologic DM; PM, polymyositis; SSc, systemic sclerosis.

$(16 / 19,84.2 \%)$. In our cohort, 6 of 7 patients with isolated anti-Ku presented typical immune-mediated necrotizing myopathy (IMNM)-like pathological features with predominantly necrotic muscle fibre and $\mathrm{CD} 68^{+}$macrophage endomysial infiltration in accordance with the 2017 European Neuromuscular Centre (ENMC) criteria for IMNM. ${ }^{6}$ However, 1 out of 6 patients with coexistence of anti-Ku and MSA presented with typical pathological features of IMNM. Classical pathologic DM such as perifascicular atrophy and normal pathologic performance were observed in anti-TIF1 $\gamma$ - and anti-MDA5-positive 

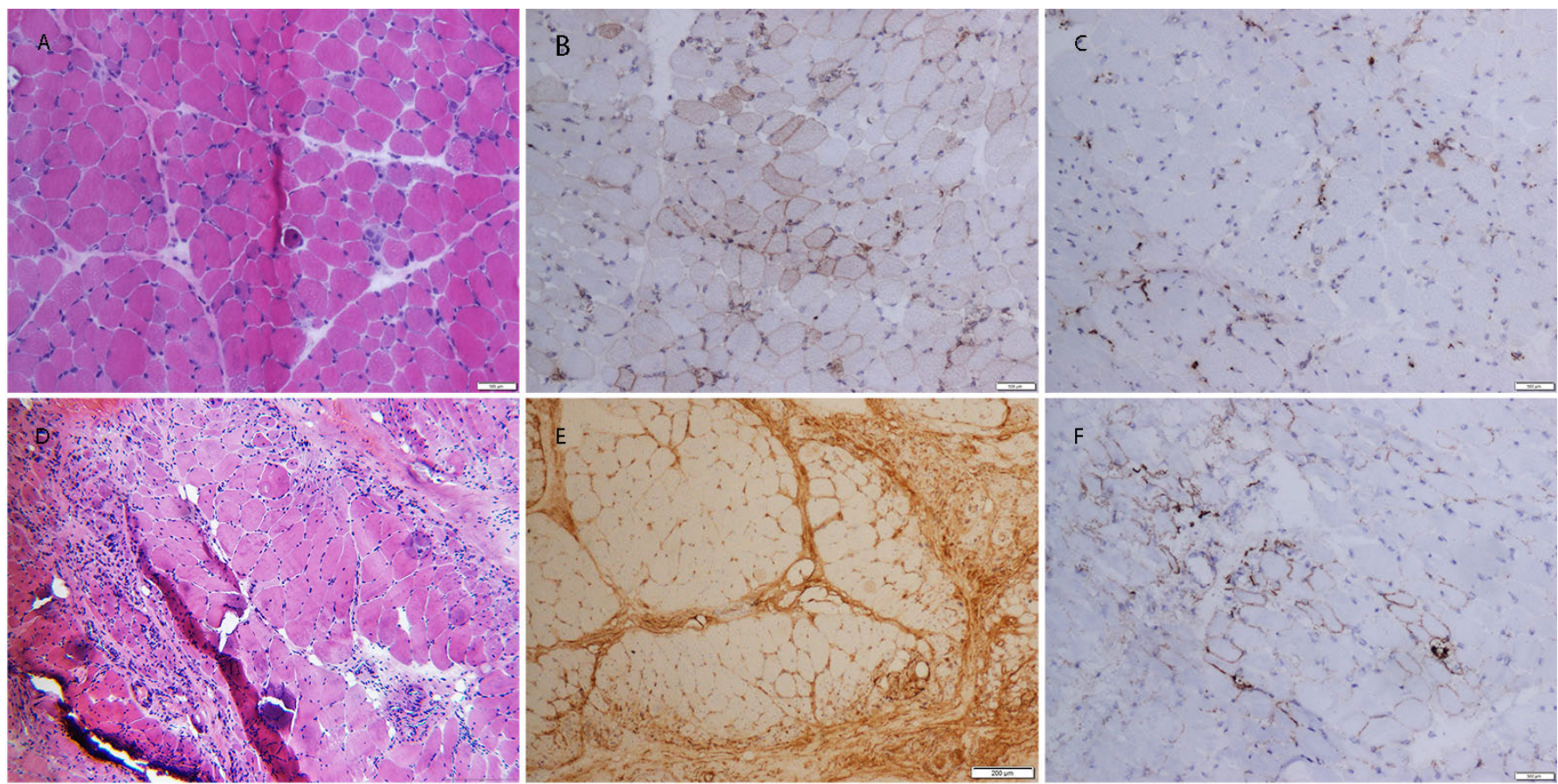

Figure $1 \mathrm{H} \& \mathrm{E}$ and immunohistochemistry staining of muscle specimens in anti-Ku-positive patients with idiopathic inflammatory myopathies (IIM). A-C, F IIM patient with isolated anti-Ku: Muscle fibre necrosis, myophagocytosis and regeneration(A), sarcolemmal MHC-I expression(B), CD68 ${ }^{+}$ cells scattered endomysial infiltration(C), sarcolemmal membrane attack complex(C5b-9) expression(F). D-E, dermatomyositis patient with anti-Ku coexistence of anti-TIF1 $\gamma$ : perifascicular atrophy(D), sarcolemmal MHC-I expression in perifascicular muscle fibre(E).

patients, respectively. In addition, 1 patient with coexistence of anti-Ku and anti-Jo-1 was diagnosed with non-specific myositis according to the 2004 ENMC classification criteria for IIM(table 1 , figure 1$)^{7}$

In conclusion, the presence of anti-Ku autoantibodies is rare among IIM patients. Concomitant ILD and elevated CK level are common features of anti-Ku positive patients. However, the clinical and pathological characteristics are distinct in patients with isolated anti-Ku and those with coexistence of anti-Ku and MSA. Skin rash is more common in patients with coexistence of anti-Ku and MSA, while severe ILD and IMNM are common in patients with isolated anti-Ku. Further studies on the characteristics of anti-Ku-positive IIM using larger cohorts are warranted.

\section{Hongxia Yang $\odot{ }^{1,2}$ Wenli Li, ${ }^{1}$ Xiaolan Tian, ${ }^{1}$ Guochun Wang, ${ }^{1}$ Xiaoming Shu, ${ }^{1}$ Qinglin Peng, ${ }^{1}$ Xin Lu ${ }^{1}$}

'Department of Rheumatology, China-Japan Friendship Hospital, Beijing, China ${ }^{2}$ China-Japan Friendship School of Clinical Medicine, Peking University, Beijing, China

Correspondence to Professor Xin Lu, Department of Rheumatology, China-Japan Friendship Hospital, Beijing 10029, China; luxin_n@163.com

Contributors HY. Yang collected and analysed data, drafted the manuscript; X. Lu conceived the hypothesis, analysed data and critically revised the manuscript and gave final approval; GC. Wang, revised the manuscript; WL. Li, XL. Tian, XM. Shu, QL. Peng collected and interpreted data. All authors have read and approved the final manuscript.

Funding This study was supported by foundation of Beijing Municipal Science and Technology Commission (Z171100001017208).

Competing interests None declared.

Patient and public involvement Patients and/or the public were not involved in the design, or conduct, or reporting, or dissemination plans of this research.

Patient consent for publication Not required.

Provenance and peer review Not commissioned; internally peer reviewed. (c) Author(s) (or their employer(s)) 2020. No commercial re-use. See rights and permissions. Published by BMJ.

$$
\text { Check for updates }
$$

To cite Yang H, Li W, Tian X, et al. Ann Rheum Dis Epub ahead of print: [please include Day Month Year]. doi:10.1136/annrheumdis-2020-217096

Received 3 February 2020

Accepted 5 February 2020

Ann Rheum Dis 2020;0:1-2. doi:10.1136/annrheumdis-2020-217096

ORCID iD

Hongxia Yang http://orcid.org/0000-0003-2324-3921

\section{REFERENCES}

1 Spielmann L, Nespola B, Séverac F, et al. Anti-Ku syndrome with elevated CK and antiKu syndrome with anti-dsDNA are two distinct entities with different outcomes. Ann Rheum Dis 2019;78:1101-6.

2 Ogawa-Momohara M, Muro Y, Akiyama M. Overlap of systemic lupus erythematosus and myositis is rare in anti-Ku antibody-positive patients. Ann Rheum Dis 2019:pii: annrheumdis-2019-216375.

3 Rigolet A, Musset L, Dubourg 0, et al. Inflammatory myopathies with antiKu antibodies: a prognosis dependent on associated lung disease. Medicine 2012:91:95-102.

4 Fernandez C, Bardin N, De Paula AM, et al. Correlation of clinicoserologic and pathologic classifications of inflammatory myopathies: study of 178 cases and guidelines for diagnosis. Medicine 2013;92:15-24.

5 Suzuki S, Yonekawa T, Kuwana M, et al. Clinical and histological findings associated with autoantibodies detected by RNA immunoprecipitation in inflammatory myopathies. J Neuroimmunol 2014;274:202-8.

6 Allenbach Y, Mammen AL, Benveniste 0, et al. 224th ENMC International workshop: clinico-sero-pathological classification of immune-mediated necrotizing myopathies Zandvoort, the Netherlands, 14-16 October 2016. Neuromuscul Disord 2018;28 :87-99.

7 Hoogendijk JE, Amato AA, Lecky BR, et al. 119th ENMC International workshop: trial design in adult idiopathic inflammatory myopathies, with the exception of inclusion body myositis, 10-12 October 2003, Naarden, the Netherlands. Neuromuscul Disord 2004; $14: 337-45$. 